\title{
Estudando o Centro Histórico de Natal (RN) e suas possibilidades para o turismo
}

\section{Studying the Historical Center of Natal (RN) and its possibilities for tourism}

\section{Patrícia Daliany Araújo do Amaral, Isabella Ludimilla Barbosa do Nascimento, Fábio Henrique da Silva}

\begin{abstract}
RESUMO
Busca analisar o potencial do Centro Histórico de Natal (RN) para o desenvolvimento de atividades relacionadas ao turismo cultural, apontando a importância deste espaço para o fortalecimento de um segmento ainda pouco desenvolvido na cidade. Para que o objetivo central fosse alcançado, foi necessário analisar suas principais edificações; verificar as estruturas físicas e as condições de acesso aos atrativos e; apontar alternativas de utilização dos referidos espaços. Trata-se de um estudo descritivoexploratório, de caráter qualitativo, que envolveu pesquisa bibliográfica e de campo. Aponta a importância da realização de um trabalho de educação patrimonial, para que a comunidade aproprie-se e se identifique com o centro histórico, valorizando-o. Esta questão pode fazer com que os espaços sejam preservados e se tornem mais atrativos aos turistas. Destaca-se, ainda, a necessidade de um trabalho de divulgação e dinamização de diversos espaços. Também devem ser consideradas questões como sinalização, acessibilidade, e informações disponíveis aos visitantes.
\end{abstract}

PALAVRAS-CHAVE: Centro Histórico de Natal; Patrimônio; Turismo Cultural.

\section{ABSTRACT}

It aims to make an analysis about the potential of the Natal's Historic Center (RN, Brazil) for the development of activities for cultural tourism, including the importance of that space to strengthening of a segment still undeveloped of the city. For reach the main purpose, it was necessary to analyze the main buildings; examine structures and access conditions of those touristic attractives; and find ways to utilize them. This is a descriptiveexploratory study, that's also has a qualitative character, which involved bibliographic and field research. Indicate the importance of a heritage education work, for the community have the opportunity to take ownership of this, identifying themselves with the historic center, and consequently, starting to valorize their own history. So, the space has a huge chance to be preserved and become more attractive for tourists. It's necessary to highlight the need of disclosure work and use of several spaces. It's necessary consider points like signaling, accessibility, and tourist informations.

KEYWORDS: Natal's Historic Center; Heritage; Cultural Tourism. 


\section{Introdução}

O artigo busca analisar o Centro Histórico de Natal (RN), a partir de uma apresentação das possibilidades de desenvolvimento do turismo cultural nessa cidade, visto que tal segmento vem crescendo e demonstrando resultados bastante positivos aos destinos turísticos que nele investem.

De acordo com uma pesquisa realizada pelo Ministério do Turismo em 2009, no qual eram investigados os hábitos de consumo dos turistas brasileiros, em relação ao principal motivo da escolha do destino turístico, conhecer a cultura e a população local aparece em terceiro lugar, com $13,2 \%$ do total dos entrevistados. Os dois primeiros lugares apontam para a busca por belezas naturais/natureza e praias, que totalizam $55,1 \%$ dos pesquisados. Este dado revela que se sobressai o número de turistas em busca de contato com a natureza, mas começa a ganhar espaço o interesse pelas questões culturais. Como Natal trata-se de um destino prioritariamente de sol e mar, agregar a questão cultural a essa oferta turística é uma possibilidade interessante para atrair um número maior de visitantes, assim como aumentar seu tempo de permanência no destino.

Como afirma Cascudo (1999), os primeiros bairros de Natal foram a Cidade Alta e a Ribeira, os quais presenciaram os primórdios da província, e deram início a um lento processo de povoação. Ainda hoje, vários prédios e monumentos da época são mantidos e alguns preservados, sendo testemunhos erguidos da história do povo natalense, a qual poderia ser contada também aos turistas que visitam a localidade e têm interesse em conhecer mais profundamente a cultura do local e da sua população.

Assim sendo, como objetivo central deste trabalho, propõe-se realizar estudo acerca do Centro Histórico de Natal, com vistas à efetivação de propostas para o desenvolvimento do turismo cultural nesta área. Para que tal objetivo fosse alcançado, foi necessário analisar o potencial turístico do Centro Histórico, através de suas principais edificações; verificar as estruturas físicas e as condições de acesso aos atrativos; assim como propor alternativas de utilização dos referidos espaços em estudo.

Trata-se de um estudo exploratório e descritivo, com uma abordagem qualitativa. Segundo Rodrigues (2007), o estudo exploratório refere-se à caracterização do problema, no qual é definida sua classificação. Desse modo, foram realizadas pesquisas bibliográficas e documentais referentes ao assunto abordado. Em relação à pesquisa descritiva, foi realizada a partir dos fatos observados e registrados, no qual não houve interferência direta do pesquisador. Para a coleta de dados, utilizou-se como procedimento metodológico a pesquisa de campo para aprofundamento de conhecimentos relacionados ao objeto de estudo, e foi realizada durante o mês de abril de 2012 no Centro Histórico de Natal.

A pesquisa justifica-se pelo fato de que turismo cultural é um segmento turístico que vem crescendo e se expandindo de maneira bastante positiva em todo o mundo. Em relação ao turismo de Natal, os principais atrativos trabalhados na venda do destino são sol e praia. Na verdade, não se trata de uma questão negativa, pois esses são recursos abundantes no Rio Grande do Norte; todavia, é preciso diversificar os rotei- 
ros ofertados à demanda real de turistas que visita Natal. Também é importante para atrair uma demanda de turistas em potencial que tem interesse específico nessa área.

Do ponto de vista da sociedade local, essa interação com o turista e a atividade turística é importante nos aspectos social e econômico, pois haverá contato da população com culturas distintas, e com a circulação de um número maior de pessoas no local, acarretará também na maior circulação de divisas. As motivações que levaram os autores à realização da pesquisa envolvem o interesse pela temática, assim como o fato de desenvolverem seus estudos relacionados à questão do patrimônio e do turismo cultural, ainda pouco desenvolvido na cidade do Natal-RN. Este artigo é resultado de uma etapa do projeto de pesquisa que estuda o Centro Histórico de Natal e suas possibilidades para o turismo cultural, no qual os estudantes são bolsistas do CNPQ (Conselho Nacional de Desenvolvimento Científico e Tecnológico).

\title{
Analisando o turismo cultural e o centro histórico de Natal
}

\section{Patrimônio e turismo cultural}

O sentido de patrimônio está relacionado com propriedade, herança paterna, dos que viveram antes e deixaram o seu legado e a sua história registrada em edificações para as futuras gerações. O patrimônio pode ser dividido em material e imaterial. O imaterial é composto pelas manifestações culturais, danças, aspectos culturais intangíveis como um todo, enquanto o material são os edifícios, monumentos, pinturas, dentre outros. Conservar essas construções é um meio de preservar e sempre lembrar fatos, acontecimentos históricos e do próprio desenvolvimento da cidade, construindo assim uma memória e criando um vínculo entre passado e o presente, por meio de afeição e de afetividade, tentando assim estabelecer uma relação e um sentimento de pertencimento do morador a sua cultura local (ABREU; CHAGAS, 2009). Todavia, o patrimônio, por si só, não dá conta de remontar e contar a história de uma cidade e de uma população. Segundo Martins (2006, p.39):

\begin{abstract}
O território em que vivemos é mais que um simples conjunto de objetos, mediante os quais trabalhamos, circulamos, moramos, mas também um dado simbólico. A linguagem regional faz parte desse mundo de símbolos, e ajuda a criar esse amálgama, sem o qual não se pode falar de territorialidade. Esta não provém do simples fato de viver num lugar, mas da comunhão que com ele mantemos.
\end{abstract}

A partir dessa afirmação, pode-se perceber que o patrimônio por si só não caracteriza uma identidade, e sim os símbolos, os significados, a relação entre a história e os aspectos que englobam esse legado com a comunidade local que preserva essa memória. Esse conjunto de valores e noções monta um cenário singular da história e do legado local, imprimindo assim a singularidade e a peculiaridade do lugar, formando sua identidade e exaltando sua importância para a sociedade. Com a valorização do patrimônio por parte do turismo, ele passará a ser mais notado e a sociedade local pode começar a enxergar os monumentos como parte integrante do seu passado e da sua história. 
A globalização e a rotina diária atribulada das grandes cidades vem trazendo grandes mudanças à sociedade. Com a intensificação desses processos, estimulouse nos homens o interesse em conhecer mais sobre sua história e seu passado. Dessa forma, essa questão abriu portas para o conhecimento de novas culturas e o compartilhamento de experiências entre elas (DIAS, 2006).

Cada vez mais, as pessoas buscam acesso às informações, inclusive nos seus momentos de lazer, quando também praticam turismo. Durante as viagens, é natural conhecer a história e o patrimônio das cidades que visitam, e que têm realidades distintas das suas. $O$ turista cultural busca conviver com essa cultura e procura interagir, tendo um contato mais próximo com a população local. A atividade do turismo cultural assume, assim, um caráter educativo e integrador, de forma que essa troca de experiências possibilita também uma troca de informação e conhecimento. Essa interação é a premissa básica para esse segmento, no qual o visitante entra em contato com os costumes, os hábitos, a história e tudo que está relacionado à população autóctone.

Geralmente, as atividades que envolvem o patrimônio incluem visitas que também são realizadas nos centros históricos, o que pode acarretar efeitos positivos. Pode-se apontar um prédio antigo que possui um fluxo de turistas, o qual dificilmente será derrubado ou vendido. Ademais, será preservado e se possível, será restaurado e adequado para atender às necessidades e interesses dos visitantes (BARRETTO, 2000). Essa preservação contribui não somente para conservar os patrimônios culturais, mas também para manter viva a história e as raízes culturais da cidade, para que a população possa se identificar com esses aspectos e criar sua própria identidade cultural. O turismo cultural é uma alternativa para fugir do turismo de massa, por se tratar de um segmento que atrai turistas com maior nível educacional e que respeitam o meio cultural e ambiental que visitam (BARRETTO, 2007). Segundo Richards (2005, p.1):

\begin{abstract}
O turismo cultural tem sido identificado como uma das áreas de maior crescimento nos últimos anos no turismo em geral. Entretanto, a pesquisa em turismo cultural não seguiu o mesmo ritmo que o crescimento do mercado. Um dos motivos da falta de pesquisas é a diversidade da "cultura" que os turistas consomem, o que, por sua vez, torna difícil definir o turismo cultural.
\end{abstract}

Apesar dessa complexidade, vários autores definem-no como sendo um segmento que se estrutura a partir da visitação ou do conhecimento, in loco, de recursos de origem cultural (COSTA, 2009). A partir disso, pode-se perceber que a história e a identidade de um povo são essenciais para a vivência do mesmo. Dessa forma, é importante para uma localidade turística que ela possua espaços capazes de apresentar a sua própria história, e demonstrar através de seus patrimônios um pouco da população local.

Se o turismo cultural for bem planejado e trabalhado, seus efeitos podem ser maximizados. Haverá a valorização do patrimônio cultural, onde a comunidade irá en- 
cará-lo como parte da sua história, e isso fortalecerá sua identidade cultural e o seu sentimento de pertença. Além disso, aumentará a circulação de pessoas de culturas distintas e este fato proporcionará o compartilhamento de informações e o desenvolvimento intelectual delas, de forma que esse aumento possibilite a melhoria ou a construção de novos estabelecimentos comerciais. Esses, por sua vez, irão gerar uma renda para comerciantes locais. Outros fatores ainda podem ser trabalhados, e podem até modificar o estilo de vida e melhorar a qualidade de vida da população local (DIAS, 2006).

Cidades históricas brasileiras, como é o caso de Ouro Preto e Salvador, investem na preservação de seu patrimônio, assim como na divulgação de roteiros de visitação aos centros históricos da cidade, o que atrai um número significativo de turistas interessados em conhecer a história do lugar e também de sua população local. Segundo Martins (2006), o que mais interessa e desperta a atenção do turista em seus momentos de viagem são os aspectos peculiares de cada destino, assim como o modo de vida da sociedade local como um todo. Dessa forma, percebe-se que um dos fatores de diferenciação entre um lugar e outro é a sua história, suas raízes, e como isso se apresenta em cada localidade.

\section{O Centro Histórico de Natal}

O Centro Histórico de Natal possui vários edifícios e um patrimônio histórico que remete a importantes acontecimentos na cidade, concentrados nos bairros da $\mathrm{Ci}$ dade Alta e da Ribeira, por serem os primeiros bairros da cidade. As primeiras movimentações e construções arquitetônicas que ainda permanecem preservadas surgiram na Cidade Alta. Algumas não são originais, mas ainda assim sua estrutura possui grande valor histórico para a cultura potiguar. O traçado urbano da cidade continua ainda em sua maioria com suas conjunturas iniciais, e apesar do tempo e do desenvolvimento urbano, a configuração das ruas e dos quarteirões ainda continua com as mesmas características da época da construção da cidade (MELO; SILVA FILHO 2007).

O seu acervo é formado por várias edificações de diversos estilos arquitetônicos construídos em distintas épocas da história. De maneira geral, algumas edificações são do período colonial, no qual apesar de alguns terem sido destruídos com o passar do tempo, ainda existem exemplares da época, de forma que retratam o início da colonização e do povoamento da cidade.

Durante o século XVII, os bairros da Cidade Alta e da Ribeira constituíam os limites da cidade, que contava com poucos moradores e também tinha como única edificação a igreja matriz. Nessa época, a cidade pouco se desenvolveu (Figura 1). 


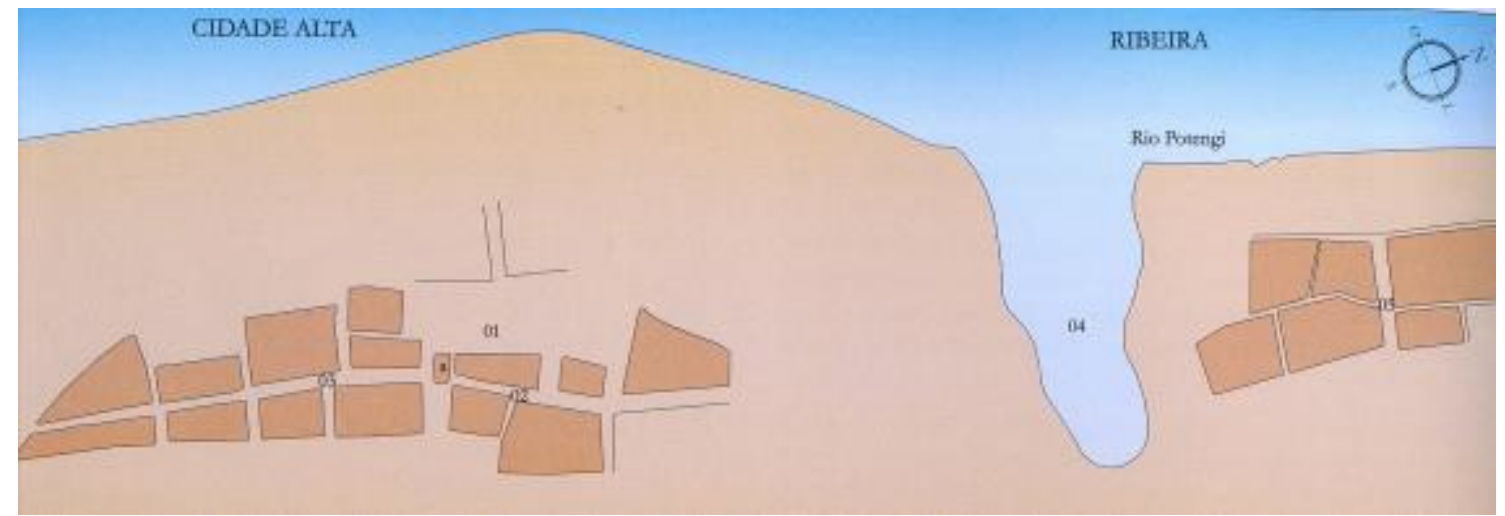

Figura 1: Mapa de Natal por volta de 1690 (imagem constituída após pesquisa documental). Fonte: Mendes (2007).

Figure 1: Map of Natal circa 1690 (image formed after documentary research).

Source: Mendes (2007).

Já no final do século XVIII, nota-se um desenvolvimento considerável na cidade em relação ao século anterior, no qual se vê mais ruas e mais construções pelos dois bairros, inclusive uma ponte interligando ambos (Figura 2).

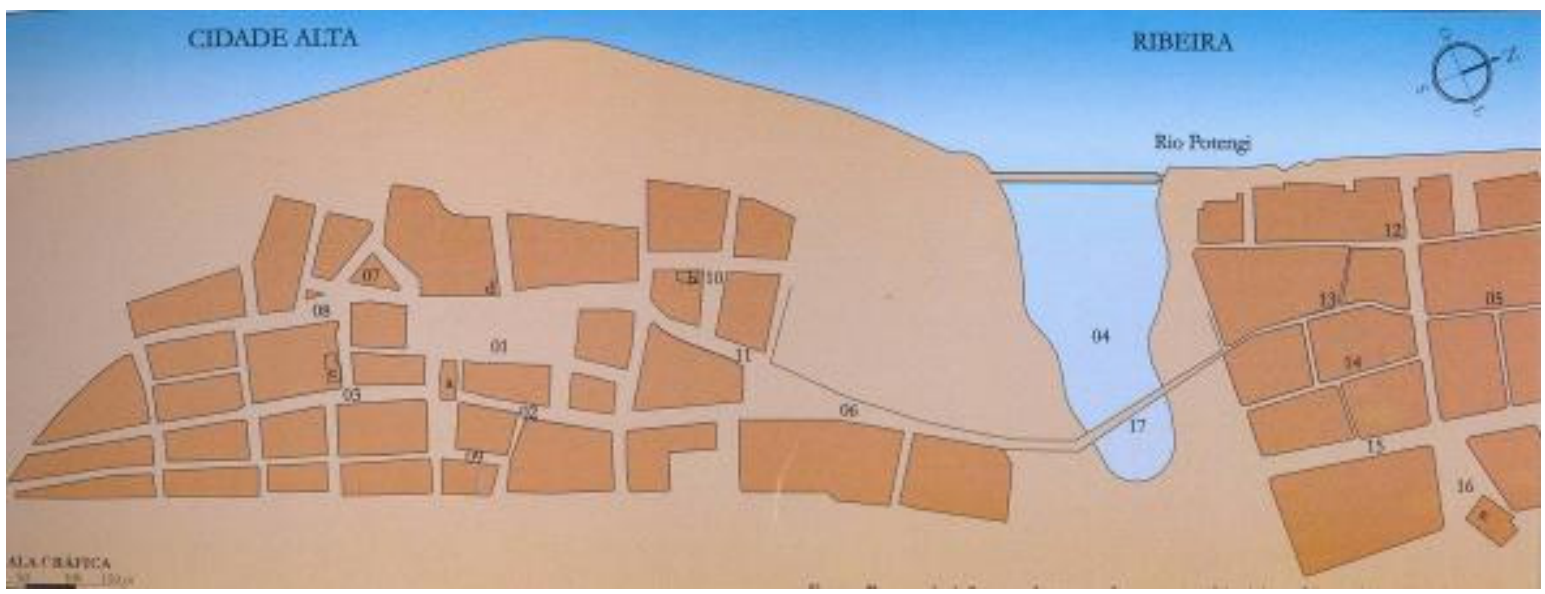

Figura 2: Mapa de Natal por volta de 1790 (imagem constituída após pesquisa documental).

Fonte: Mendes (2007).

Figure 2: Map of Natal circa 1790 (image formed after documentary research).

Source: Mendes (2007).

Não somente o número de edificações cresceu, mas a dinâmica social e o comércio ficaram mais intensos. Mas apesar disso, Natal ainda não se configurava como uma grande cidade e crescia a curtos passos, conforme aponta a descrição de Natal, por Henry Koster: 
As construções foram feitas numa elevação a pequena distância do rio, formando a cidade propriamente dita porque contém a Igreja Matriz. Consiste numa praça cercada de residências, tendo apenas o pavimento térreo, as igrejas que são três, o palácio, a câmara e a prisão. Três ruas desembocam nesta quadra, mas elas não possuem senão algumas casas de cada lado. A cidade não é calçada em parte alguma e anda-se sobre uma areia solta, o que obrigou alguns habitantes a fazerem calçadas de tijolos ante suas moradas. Esse lugar contará seiscentos ou setecentos habitantes. [...] (KOSTER, 1978, p. 110).

À tarde, saímos passeando para ver a cidade baixa. É situada nas margens do rio e as casas ocupam as ribas meridionais e não há, entre elas e o rio, senão a largura da rua. Essa parte pode conter 200 a 300 moradores e aí residem os negociantes do Rio Grande (KOSTER, 1978, p.110).

Como é possível verificar, o primeiro trecho trata do bairro da Cidade Alta, cuja infraestrutura ainda continuava sem grandes avanços e sem grande desenvolvimento das construções. O segundo trecho descreve o bairro da Ribeira, que concentrava a parte comercial de Natal, até então pouco desenvolvida. Somente no final do século XVIII e início do século XIX que realmente há mudanças e avanços na cidade, com a sua urbanização e modernização de sua infraestrutura.

Em um contexto mais abrangente, o estilo neoclássico toma conta do Brasil por volta do século XIX, através da influência dos franceses. Natal incluiu-se nesse contexto. Várias edificações importantes para a história potiguar representam as características desse estilo e exaltam a sutileza e a beleza de seus traços, no qual se encontram em boa conservação (MELO; SILVA FILHO, 2007).

A partir do século XIX, Natal realmente inicia seu desenvolvimento urbano e a cidade começa a crescer e a construir cada vez mais edifícios. Na ocasião, o estilo predominante dessas construções foi o ecletismo, de forma que o mesmo não possui traços ou características próprias, ele agrega propriedades de outros estilos distintos e os misturam de modo a ressaltar o melhor de cada um. Outras técnicas são retratadas nos patrimônios do centro histórico, mas esses são os principais e mais recorrentes, e ajudam a remontar a história e a memória da comunidade local e estabelecer uma ligação entre os acontecimentos do passado e a identificação dos potiguares com o seu legado (MELO; SILVA FILHO, 2007).

Os Quadros 1 e 2 apresentam alguns dos edifícios que se destacam nos bairros em estudo, apontando suas principais características e questões acerca da acessibilidade e das atividades desenvolvidas: 
Quadro 1: Edifícios do bairro da Cidade Alta que possuem potencial turístico.

Table 1: Building neighborhood of Uptown that have tourism potential.

\begin{tabular}{|c|c|c|c|}
\hline Edifício & Descrição & Acessibilidade & Atividades ofertadas \\
\hline Igreja do Galo & $\begin{array}{l}\text { Terceiro templo religioso da cidade. De } \\
\text { estilo barroco, possui um galo em sua torre } \\
\text { lateral como um de seus principais traços. } \\
\text { Engloba o convento de Santo Antônio e o } \\
\text { Museu de Arte Sacra }\end{array}$ & $\begin{array}{l}\text { Possui rampa na calça- } \\
\text { da, porém a entrada da } \\
\text { igreja não possui. }\end{array}$ & $\begin{array}{l}\text { Missa, exposição de } \\
\text { obras e objetos no Mu- } \\
\text { seu de Arte Sacra e } \\
\text { visita ao Convento de } \\
\text { Santo Antônio }\end{array}$ \\
\hline $\begin{array}{l}\text { Memorial Câmara } \\
\text { Cascudo }\end{array}$ & $\begin{array}{l}\text { Construído no final do século XIX para abri- } \\
\text { gar a Sede da Fazenda. Hoje, homenageia } \\
\text { o folclorista potiguar Luís da Câmara Cas- } \\
\text { cudo, e guarda grande acervo de seu traba- } \\
\text { lho }\end{array}$ & $\begin{array}{l}\text { Possui rampa na calça- } \\
\text { da, porém a entrada não } \\
\text { disponibiliza rampa }\end{array}$ & $\begin{array}{l}\text { Exposição de objetos } \\
\text { ligados ao folclore e à } \\
\text { cultura popular, além de } \\
\text { objetos pessoais e ho- } \\
\text { menagens a Câmara } \\
\text { Cascudo }\end{array}$ \\
\hline $\begin{array}{l}\text { Igreja de Nossa Se- } \\
\text { nhora da Apresenta- } \\
\text { ção }\end{array}$ & $\begin{array}{l}\text { Conhecida como antiga catedral. Primeiro } \\
\text { templo religioso construído na cidade, a } \\
\text { edificaçãa atual foi construída em cima da } \\
\text { antiga capelinha que havia ali, havendo } \\
\text { ainda ruínas da mesma dentro da igreja }\end{array}$ & $\begin{array}{l}\text { Possui rampa na calça- } \\
\text { da, porém a entrada da } \\
\text { igreja não possui }\end{array}$ & $\begin{array}{l}\text { Missa e visitação guiada } \\
\text { no período vespertino }\end{array}$ \\
\hline $\begin{array}{l}\text { Praça André de Albu- } \\
\text { querque }\end{array}$ & $\begin{array}{l}\text { Marco de início do desenvolvimento da } \\
\text { cidade. Ao seu redor foi construída a igreja } \\
\text { matriz e as construções mais importantes } \\
\text { da época, como Casa de Câmara e Cadeia } \\
\text { e Tesouraria da Fazenda. Algumas dessas } \\
\text { construções continuam preservadas }\end{array}$ & $\begin{array}{l}\text { Possui rampas na calça- } \\
\text { da }\end{array}$ & $\begin{array}{l}\text { Espaço público de lazer } \\
\text { da cidade, com ativida- } \\
\text { des culturais que acon- } \\
\text { tecem esporadicamente }\end{array}$ \\
\hline $\begin{array}{l}\text { Igreja de Nossa Se- } \\
\text { nhora do Rosário }\end{array}$ & $\begin{array}{l}\text { Segundo templo religioso construído em } \\
\text { Natal. Foi construída para que os negros } \\
\text { assistissem a missa separados dos brancos }\end{array}$ & $\begin{array}{l}\text { Possui vários degraus } \\
\text { em sua entrada }\end{array}$ & $\begin{array}{l}\text { Missa, incluindo uma } \\
\text { missa rezada em latim } \\
\text { uma vez por semana, } \\
\text { nos domingos pela ma- } \\
\text { nhã }\end{array}$ \\
\hline $\begin{array}{l}\text { Palácio Felipe Cama- } \\
\text { rão }\end{array}$ & $\begin{array}{l}\text { Prédio com predominância arquitetônica do } \\
\text { estilo eclético, foi inaugurado em } 1922 \text { e } \\
\text { abriga e é a sede do Governo Municipal de } \\
\text { Natal }\end{array}$ & $\begin{array}{l}\text { Possui vários degraus } \\
\text { em sua entrada }\end{array}$ & $\begin{array}{l}\text { Aberto ao público para } \\
\text { visitação do edifício em } \\
\text { horário comercial }\end{array}$ \\
\hline Palácio Potengi & $\begin{array}{l}\text { Construído em meados de } 1873 \text {, predomina } \\
\text { o estilo neoclássico. Sempre teve utilidade } \\
\text { pública, funcionando como Tesouraria Pro- } \\
\text { vincial, Repartição do Correio, Câmara Mu- } \\
\text { nicipal, Júri. Hoje é a Pinacoteca do Estado }\end{array}$ & $\begin{array}{l}\text { Possui rampa na calça- } \\
\text { da, porém a entrada } \\
\text { principal não possui }\end{array}$ & $\begin{array}{l}\text { Exposição de quadros e } \\
\text { apresentações culturais }\end{array}$ \\
\hline Capitania das Artes & $\begin{array}{l}\text { Concluído no final do século XIX, abrigou a } \\
\text { Capitania dos Portos até a década de 1970, } \\
\text { ficando posteriormente abandonado. Ape- } \\
\text { nas a fachada é restaurada }\end{array}$ & $\begin{array}{l}\text { Possui um degrau na } \\
\text { sua entrada principal, } \\
\text { porém, o acesso ao } \\
\text { prédio contém uma ram- } \\
\text { pa }\end{array}$ & $\begin{array}{l}\text { Galeria de arte e apre- } \\
\text { sentações culturais }\end{array}$ \\
\hline Solar Bela Vista & $\begin{array}{l}\text { Construído no início do século XX para ser } \\
\text { a residência de um rico coronel. Foi Tribunal } \\
\text { de Justiça e um luxuoso hotel. Funciona } \\
\text { como Centro de Cultura e Lazer do SESI }\end{array}$ & $\begin{array}{l}\text { Possui vários degraus } \\
\text { em sua entrada }\end{array}$ & Apresentações culturais \\
\hline Instituto Ludovicus & $\begin{array}{l}\text { Moradia do potiguar mais ilustre, o jornalis- } \\
\text { ta, escritor e folclorista Câmara Cascudo. } \\
\text { Criado em sua homenagem, abriga suas } \\
\text { obras e seus objetos pessoais }\end{array}$ & $\begin{array}{l}\text { Possui vários degraus } \\
\text { em sua entrada }\end{array}$ & $\begin{array}{l}\text { Exposição de objetos e } \\
\text { obras de Câmara Cas- } \\
\text { cudo }\end{array}$ \\
\hline
\end{tabular}

Fonte: Dados da pesquisa (2012).

Source: Survey data (2012). 
Quadro 2: Edifícios do bairro da Ribeira que possuem potencial turístico.

Table 2: Building the Ribeira district that have tourism potential.

\begin{tabular}{|c|c|c|c|}
\hline Edifício & Descrição & Acessibilidade & Atividades ofertadas \\
\hline $\begin{array}{l}\text { Museu de Cultura Popular } \\
\text { Djalma Maranhão }\end{array}$ & $\begin{array}{l}\text { Construído para ser o termi- } \\
\text { nal rodoviário em } 1963 \text {. Foi } \\
\text { restaurado e abriga o Mu- } \\
\text { seu de Cultura Popular } \\
\text { Djalma Maranhão }\end{array}$ & $\begin{array}{l}\text { Possui uma escadaria em } \\
\text { sua entrada }\end{array}$ & $\begin{array}{l}\text { Exposição de obras, obje- } \\
\text { tos e quadros que remetem } \\
\text { à cultura popular do RN }\end{array}$ \\
\hline Teatro Alberto Maranhão & $\begin{array}{l}\text { Concluído no início do sé- } \\
\text { culo XX, passou por várias } \\
\text { reformas. O estilo eclético } \\
\text { está presente em sua arqui- } \\
\text { tetura. }\end{array}$ & $\begin{array}{l}\text { Possui rampas de acesso } \\
\text { em sua entrada }\end{array}$ & $\begin{array}{l}\text { Apresentações teatrais } \mathrm{e} \\
\text { musicais }\end{array}$ \\
\hline Grande Hotel & $\begin{array}{l}\text { Foi o primeiro grande hotel } \\
\text { da cidade, construído na } \\
\text { década de } 1930 \text {. Hospedou } \\
\text { várias personalidades, in- } \\
\text { cluindo grande artistas e } \\
\text { militares durante a Segunn- } \\
\text { da Guerra Mundial }\end{array}$ & $\begin{array}{l}\text { Possui uma escadaria em } \\
\text { sua entrada }\end{array}$ & $\begin{array}{l}\text { No local, funcionam varas } \\
\text { do juizado cível }\end{array}$ \\
\hline Casa da Ribeira & $\begin{array}{l}\text { Construído na primeira } \\
\text { década do século XX, já foi } \\
\text { hospedaria, oficina de navi- } \\
\text { os, padaria e loja de materi- } \\
\text { al de construção. Atualmen- } \\
\text { te é um espaço cultura, } \\
\text { com teatro, café e sala de } \\
\text { exposições }\end{array}$ & $\begin{array}{l}\text { Possui rampa em sua en- } \\
\text { trada, porém, alguns locais } \\
\text { internos possui apenas uma } \\
\text { escadaria como acesso }\end{array}$ & $\begin{array}{l}\text { Apresentações teatrais e } \\
\text { musicais, sala de exposição } \\
\text { e biblioteca com livros de } \\
\text { arte e literatura em geral }\end{array}$ \\
\hline Beco da Quarentena & $\begin{array}{l}\text { Uma pequena via que era } \\
\text { frequentada por prostitutas } \\
\text { e marinheiros com doen- } \\
\text { ças. A polícia utilizava o } \\
\text { beco para acuar os bader- } \\
\text { neiros. }\end{array}$ & $\begin{array}{l}\text { Calçamento em paralepípe- } \\
\text { do, de difícil acesso para } \\
\text { cadeirantes }\end{array}$ & Espaço público \\
\hline $\begin{array}{l}\text { Antigo Palácio do Gover- } \\
\text { no }\end{array}$ & $\begin{array}{l}\text { Construído no século XIX, } \\
\text { foi uma das sedes do Go- } \\
\text { verno. Abrigou também um } \\
\text { dos bares mais famosos da } \\
\text { Ribeira. Foi restaurado e } \\
\text { atualmente é sede da Esco- } \\
\text { la de Dança do Teatro Al- } \\
\text { berto Maranhão }\end{array}$ & $\begin{array}{l}\text { Possui uma escadaria em } \\
\text { sua entrada }\end{array}$ & Aulas de dança \\
\hline Rua Chile & $\begin{array}{l}\text { Rua mais antiga da Ribeira, } \\
\text { abriga vários comércios e } \\
\text { armazéns, além de várias } \\
\text { fachadas preservadas. } \\
\text { Possui vários bares e casas } \\
\text { noturnas }\end{array}$ & $\begin{array}{l}\text { Calçamento em paralepípe- } \\
\text { do }\end{array}$ & $\begin{array}{l}\text { Espaço público, mensal- } \\
\text { mente ocorre apresenta- } \\
\text { ções culturais durante o } \\
\text { evento "Circuito Cultural da } \\
\text { Ribeira" }\end{array}$ \\
\hline
\end{tabular}

Fonte: Dados da pesquisa (2012).

Source: Survey data (2012).

É importante ressaltar que o patrimônio material edificado dos dois bairros contempla um número significativo de edifícios que possui potencial e podem ser trabaIhados em relação ao turismo cultural. Aqui, foram elencados apenas alguns deles, os quais foram escolhidos em função de sua atratividade e atividades desenvolvidas. 
A partir da evolução e do desenvolvimento que Natal sofreu e da preservação de alguns dos seus primeiros prédios e monumentos, pode-se remontar e contar a história dos primórdios da cidade, que é o legado do povo potiguar e é bastante diversificado e rico, no qual se tem muito potencial em desenvolver um roteiro para que outras pessoas também possam conhecer o Centro Histórico, despertando esse interesse não apenas dos turistas, mas também da população local.

\section{Propostas para o turismo cultural no Centro Histórico em estudo}

O turismo cultural é um segmento em desenvolvimento e uma prática bastante utilizada em vários destinos turísticos, inclusive em cidades brasileiras, como Ouro Preto e Salvador. Há também muitos outros sucessos com o segmento na Europa, por exemplo (FUNARI; JAIME, 2003). Apesar dos casos bem-sucedidos e da comprovação de que a cultura é capaz de atrair fluxos de turistas, Natal ainda não desenvolveu essa área e não atentou em demonstrar as possibilidades de atividades que existem em seu Centro Histórico.

Para trabalhar e desenvolver o segmento, é necessário que haja uma estrutura básica para a propagação desses elementos, além de quesitos como o acesso aos bairros da Cidade Alta e Ribeira. É importante que as pessoas possam locomover-se pelas ruas e ter a sinalização adequada, que auxilie no seu deslocamento. Além disso, também é interessante que sejam disponibilizadas informações a respeito do patrimônio, de modo que ao chegar a algum local, o visitante tenha a sua descrição básica e/ou alguém disponível para acompanhar a visita e explanar sobre o local e esclarecer todas as dúvidas recorrentes.

Nota-se também uma deficiência não apenas nas questões estruturais do centro histórico, mas um fator recorrente também é a questão da divulgação. Os atrativos principais de Natal são o sol e a praia, aspectos ligados às belezas naturais - não tirando o valor que esses elementos têm para a cidade - mas reconhecendo a importância que o centro histórico possui e o seu rico potencial que ainda não é explorado. Trata-se de aspectos amplamente promovidos, enquanto o segmento cultural é esquecido pelos empresários do trade turístico e até mesmo pela população, que não conhece o valor de sua história (MELO; MENEZES, 2010).

Os passeios tradicionalmente comercializados pelas agências de turismo é baseado em explanações e descrições do local, da maneira tradicional, como ocorre em vários locais. Mas o ideal é que essa apresentação seja feita de forma mais dinâmica e que interaja mais com os turistas. Para isso, é preciso pensar em estratégias que diferenciem o modo em que o roteiro é apresentado, propondo um aprendizado lúdico a respeito dos patrimônios.

Algumas atividades são apresentadas como sugestões para serem desenvolvidas nos espaços em estudo, a saber: na Praça André de Albuquerque - que inclui o marco zero da cidade do Natal - pode-se pensar na utilização de fotos e na explanação não apenas de fatos, mas também de curiosidades sobre o local, de forma que haverá uma comparação entre como a cidade era e o que ela tornou-se no decorrer do tempo, além de acrescentar histórias interessantes sobre o seu contexto. 
Outros recursos, além da questão do comparativo com as fotos, podem ser viabilizados. Por exemplo, é possível utilizar material multimídia que poderia mostrar, de forma breve e interativa, o centro histórico e algumas informações adicionais sobre o local visitado, no qual seria mostrado ao final do city tour e auxiliaria também na fixação das informações que foram passadas durante a visitação.

Ademais, outras propostas que poderiam ser utilizadas seriam a apresentação de danças folclóricas, reforçando a cultura potiguar e estimulando os artistas locais. Essa exibição poderia ser feita ao final de todo o percurso, onde os turistas visitariam a parte histórica da cidade e após apreciariam a manifestação artística da cidade. Essa apresentação poderia ser feita no Museu de Cultura Popular Djalma Maranhão (Figura 3), localizado na Praça Augusto Severo (Ribeira), local que possui um considerável acervo sobre os artistas populares potiguares e dispõe ainda de salas com telões para exibição de vídeos e um local para exposições. Ainda ali na praça, encontra-se também um outro elemento importante em termos históricos e arquitetônicos, o Teatro Alberto Maranhão (Figura 4).

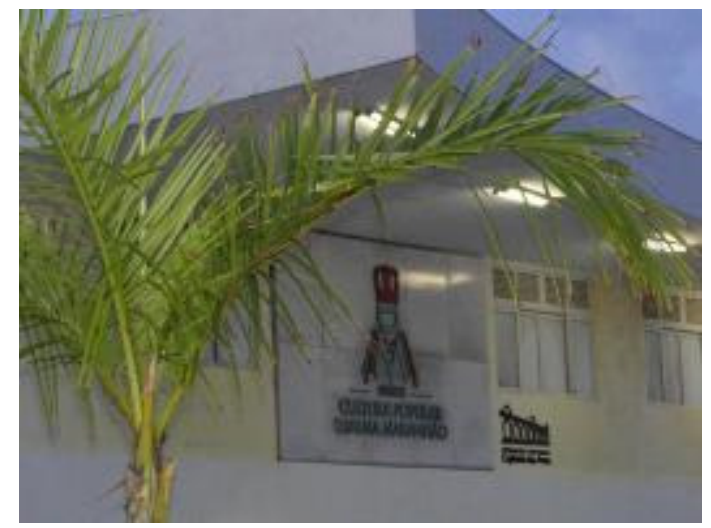

Figura 3: Museu de Cultura Popular.

Foto: Patrícia Amaral (2011).

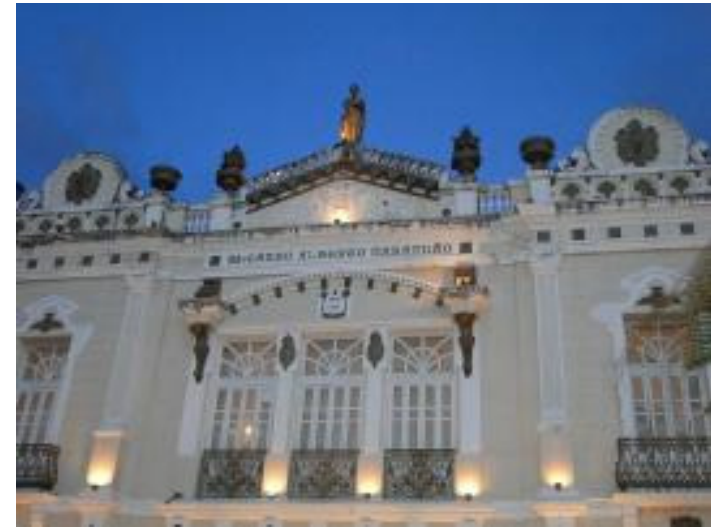

Figura 4: Teatro Alberto Maranhão. Foto: Patrícia Amaral (2011).

Todavia, para que seja implementado esse tipo de turismo, é primordial que a comunidade local esteja envolvida, não somente na questão econômica, quando pode comercializar seus produtos, mas também em outras atividades. É preciso haver uma identificação com o local e com a sua história. Pensando nesse viés, a realização de trabalhos de educação patrimonial é algo importante para que a comunidade também dele se aproprie, identificando-se e, assim, valorizando o mesmo, o que pode fazer com que os espaços sejam preservados e se tornem mais atrativos aos turistas. A partir desse reconhecimento, será possível demonstrar a outras pessoas os valores da cultura potiguar e a importância do centro histórico como objeto de memória na vida das pessoas e na formação da sua história, daí a importância da efetivação de projetos de educação patrimonial. 


\section{Conclusão}

O Centro Histórico de Natal é rico em relação ao seu patrimônio cultural, pois possui prédios com diferentes estilos arquitetônicos, construídos em distintas épocas. Eles são capazes de representar momentos históricos da cidade, fato ainda pouco explorado na perspectiva do turismo cultural. Os visitantes que vêm a Natal estão focados nas praias e belezas naturais da cidade e do seu entorno, e os aspectos culturais são pouco divulgados, não havendo também um grande interesse em promovê-lo por parte do trade turístico, e especialmente pelos restritos investimentos realizados pelo poder público.

Os edifícios localizados no centro histórico são inúmeros, ofertando algumas atividades aos seus visitantes. Contudo, há questões de infraestrutura que precisam ser revistas, como a questão da acessibilidade em diversos espaços, assim como a própria questão da sinalização interpretativa. É preciso, ainda, dinamizar os equipamentos, para que estejam efetivamente prontos para receber o público de turistas.

Mas esse não é o único problema encontrado nos bairros da Cidade Alta e da Ribeira, objeto do presente estudo. Deve ser levada em consideração também a falta de identificação das pessoas com os patrimônios e monumentos, de modo que a valorização deve vir primeiro da comunidade local e depois das pessoas que venham a visitá-lo, tendo-se, assim, uma questão mais ampla e abrangente. Aponta-se, assim, a importância da realização de trabalhos de educação patrimonial junto à comunidade local.

A atividade turística deve ser trabalhada no sentido de acrescentar e desenvolver o centro histórico, de modo que irá dinamizar a economia na região e estabelecer um intercâmbio cultural entre as pessoas, além de estabelecer uma utilização desses espaços culturais. $O$ aproveitamento dos espaços pode contribuir na preservação dos ambientes em uso e garantir que reparos sejam feitos para meIhorar as estruturas físicas e as condições de acesso ao objeto de estudo em questão.

A pesquisa foi feita no sentido de desenvolver uma discussão a respeito da utilização do centro histórico como atrativo turístico da cidade do Natal. É uma área carente em relação a pesquisas e estudos, mas há várias iniciativas que tentam propor formas de estimular e alavancar esse segmento, mas muito ainda precisa ser feito para que este espaço seja reconhecido e valorizado.

\section{Referências bibliográficas}

ABREU, R.; CHAGAS, M. (Org.). Memória e patrimônio: ensaios contemporâneos. 2. ed.Rio de Janeiro: Lamparina, 2009.

BARRETTO, M. Cultura e turismo: Discussões contemporâneas. Campinas, SP: Papirus 2007. - (Coleção Turismo) 
BARRETTO, M. Turismo e legado cultural: As possibilidades do planejamento. Campinas, SP: Papirus, 2000. - (Coleção Turismo)

CASCUDO, L.C. História da cidade do Natal. Natal (RN): RN Econômico, 3. ed 1999.

COSTA, F.R. Turismo e patrimônio cultural: interpretação e qualificação. São Paulo: Editora Senac São Paulo: Edições SESC SP, 2009.

DIAS, R. Turismo e patrimônio cultural: recursos que acompanham o crescimento das cidades. São Paulo: Saraiva, 2006.

FOSTER, G.M. As culturas tradicionais e o impacto da tecnologia. São Paulo: Fundo de Cultura, 1964.

FUNARI, P.P.; PINSKY, J. (orgs). Turismo e patrimônio cultural. São Paulo: Contexto, 2003. 3를 - (Coleção Turismo Contexto)

KOSTER, H. Viagens ao Nordeste do Brasil. Recife: Secretaria de Educação e Cultura, 1978 (Coleção Pernambucana, vol. XVII).

MARTINS, C. (Org.). Patrimônio cultural: da memória ao sentido do lugar. São Paulo: Roca, 2006.

MELO, M.A.W.S.; MENEZES, S.V.A. Um novo olhar para o corredor cultural: proposta de modelos de city tours para a cidade do Natal/RN. Trabalho de Conclusão do Curso de Turismo. Universidade Potiguar. Natal, 2010.

MENDES, C. Centro histórico de Natal. Iphan: Natal, 2007.

MINISTÉRIO DO TURISMO. Pesquisa de hábitos de consumo do turismo brasileiro. 2009. Disponível em:

http://www.dadosefatos.turismo.gov.br/export/sites/default/dadosefatos/ demanda turistica/pesquisa habitos/

Download pesquisa habitos/13.11.09 Pesquisa Hxbitos 2009.pdf Acesso em 25 jan 2012.

RICHARDS, G. Nuevos caminos para El turismo cultural? Barcelona: Diputación de Barcelona / Association for Tourism And Leisure Education - Atlas/ Observatorio Interarts, 2005, disponível em http://www.diba.es . Acesso em 25 jan 2012.

RODRIGUES, W.C. Metodologia científica. Disponível em:

http://professor.ucg.br/siteDocente/admin/arquivosUpload/3922/material/Willian\% 20Costa\%20Rodrigues metodologia cientifica.pdf . Acesso em 30 jan 2012. 
Patrícia Daliany Araújo do Amaral: Instituto Federal de Educação, Ciência e Tecnologia do Rio Grande do Norte, Natal, RN, Brasil.

Email: pdaliany@hotmail.com

Link para o currículo Lattes: http://lattes.cnpq.br/6276197262789514

Isabella Ludimilla Barbosa do Nascimento: Instituto Federal de Educação, Ciência e Tecnologia do Rio Grande do Norte, Natal, RN, Brasil.

Email: isabella_ludimilla@hotmail.com

Link para o currículo Lattes: http://lattes.cnpq.br/0935409945176042

Fábio Henrique da Silva Gomes: Instituto Federal de Educação, Ciência e Tecnologia do Rio Grande do Norte, Natal, RN, Brasil.

Email: faabio.henrique@hotmail.com

Link para o currículo Lattes: http://lattes.cnpq.br/5222976964204691

Data de submissão: 30 de maio de 2012

Data de recebimento de correções: 02 de julho de 2013

Data do aceite: 04 de julho de 2013

Avaliado anonimamente 